International Journal of Engineering \& Technology, 9(2)(2020) 572-581
International Journal of Engineering \& Technology
SPC
Website: www.sciencepubco.com/index.php/IJET
Research paper

\title{
Design and fabrication of high productive barbecue machine
}

\author{
Usman Ghani $^{1 *}$, Mubashir Hayat ${ }^{1}$, Tufail Habib ${ }^{2}$, Alam Zeb ${ }^{2}$, Khizar Azam ${ }^{2}$ \\ ${ }^{1}$ Department of Mechanical Engineering, University of Engineering and Technology Peshawar, Jalozai Campus \\ ${ }^{2}$ UET Peshawar \\ *Corresponding author E-mail: usmanghani@uetpeshawar.edu.pk
}

\begin{abstract}
Conventional methods to use a metal cavity having charcoal assisted with skewers in getting the final barbecue encounter a lot of limitations such as time, lower productivity, single temperature heating, worker fatigue, controlling of heat and time, energy consumption, importability, unhygienic food preparation (road-side open barbecuing) and cost-effectiveness etc. The proposed research considers the design and fabrication of barbecue machine fueled with gas and actuated by electrical cum mechanical systems. This electromechanical semi-automatic barbecue machine overcomes the stated limitations. It will be an important tool used for household as well as commercial use. This machine capacity is to barbecue an average of $4.5 \mathrm{~kg}$ of meat at a time. The machine is divided into three chambers. In first chamber barbecue is kept on lower temperature for high time. Once it completes its first stage motor attached with chain drive mechanism is activated and it brings the food to second chamber. In the second chamber, it takes lower time on high temperature and when it finishes it is conveyed to first chamber for un-feeding. The aim of this research is also to commercialize the product in the market targeting small scale industries and people involved in road side barbecue production, restaurants and other organizations.
\end{abstract}

Keywords: Barbecue; Electromechanical Semi-Automatic Machine; Chain Drive System; Gas Consumption Rate; Hygienic Food

\section{Introduction}

Barbecuing is very significant and time-consuming action by any household users. In commercial restaurants it is so tedious activity that it needs higher workmanship due to much material handling and process control involved in flipping and time monitoring. Certain barbecuing methods and equipment were innovated to reduce the manual work. In conventional methods to barbecue one get results such as high lead time, heavy exposure of workers to unwanted smoky air, improper heat/time management and unsafe activity for worker as heat waves come out of the manual barbecue machines. Pakistan is very populated country and its population is growing day by day. Since the food demand especially of meat products is also increasing. Pakistan comes in top 10 countries in beef consumption. Out of these meat products a huge part is grilled on gas and charcoal grills. To fulfill this demand, a lot of times a less expensive, low quality and unhygienic methods are adopted. Development of food industry is a prime factor for any country's sustainability which is related with health, economy and entertainment etc. Thus there is a need of the efficient processing of food and products which are directly or indirectly used by people. Heat and time control are the next advancement in the development of barbecue machines. Controlling time and heat during barbecuing in the barbecue machines is important in terms of improving efficiency of such machines, which increase the food quality by retaining the food ingredients and requires less energy (fuel) to barbecue unit (1 kg) food. Barbecue machines vary in sizes, mode of operation and fuel used. On the basis of heat source grills are categorized as gas, charcoal, solar and electric grills. Most widely used grills are charcoal and gas grills. Manual methods such as vents and elevation changes are used to control the temperature in charcoal grills. Gas grills are most suitable for time and temperature control as gaseous form enable us to measure and control the flow of gas leading to variation in the temperature patterns in the cooking space. Manual charcoal barbecue is very popular in Pakistan. But on large scale and mass production it is very time consuming and labor-intensive job. On the other hand low production rates in restaurants don't fully satisfy the customers. Our project seeks to overcome this problem because in manual barbecuing heat is dispersed randomly in every direction whereas in our machine the fuel supply is cut off when it is not needed and secondly it is environmentally sealed that don't dissipate heat to surrounding. This project involves the process of designing different parts of barbecue machine considering the forces, thermal effects and ergonomic factors of people to use. This project is mainly about generating new concept of barbecue machine that would easier and hygienic to use. To overcome the deficiencies and problems in the existing barbecue machines and to achieve best performance from barbecue machine the limits mentioned above should be optimized.

\subsection{Problem statement}

In Pakistan charcoal/gas grilling is continued on expanding with high pace which consists of open shaped structure, exposed to environment and are usually used on the roadside and restaurants as shown in figure 1. Dusts from surrounding space come through top and become the part of grilled food which is perilous to human health. These BBQ machines do not comply with hygienic standards issued by pure food 
ordinance 1960 (for preparation, sales and preventing adulteration of food products) and the law of 1963 which was then revised in 2007 and 2011.
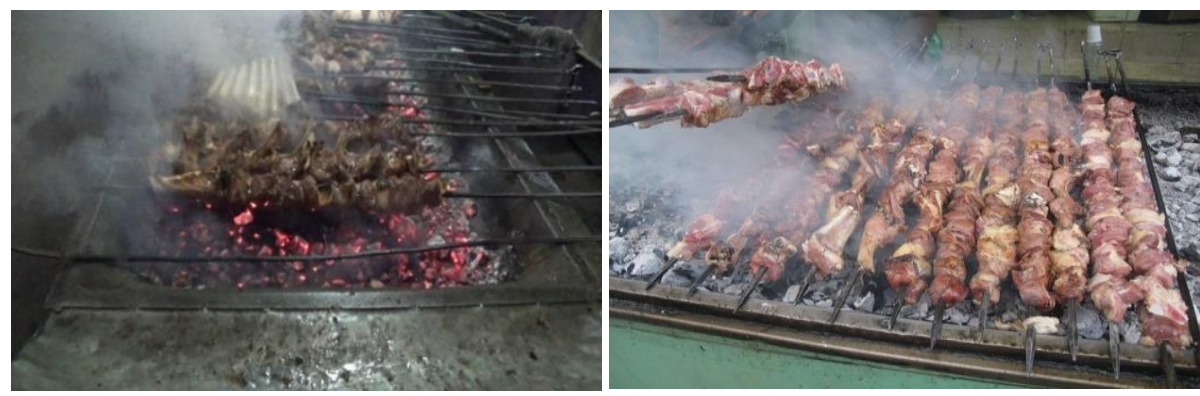

Fig. 1: Charcoal Barbecuing in Local Pakistani Market.

Apart from this, there are a lot of additional food quality and operational issues such as:

- Heat is not distributed even on the barbecue surface and it result in overcook on the edges and raw from the middle

- Productivity is low because of mismanagement of processing and lack of automation

- This method uses single temperature heating which spoils food ingredients; foods do not lose ingredient if it is barbecued over two time-temperature sets, when initially it is smoked for high time and lower temperature and then use high temperature for shorter time.

- Flipping skewers randomly and time to time is labor-intensive job for workers and it also reduce the productivity in terms of lead time

- Most of energy is lost to environment in form of heat in manual barbecuing and its fossil fuel is not conserved. This results in lower energy efficiency of manual machines.

- Light particle of ashes flies to stick on the barbecue surface when manual fan is used during barbecuing, causes health infections

- High lead time due to unnecessary operational activities, high setup time and manual moves

- Health issues because of carcinogenetic meat

\subsection{Aims and objectives}

There is needed to design, model and construct a new BBQ machine that will overcome the above stated problems. This research seeks to design and fabricate a gas-fueled BBQ machine which will present a great solution to problems related with current BBQ machines. Key aims and objectives of the work are as follow:

- To distribute the heat uniformly around the surface of barbecue to get identical surface cooking

- To increase the productivity by combining mechanical systems and automation

- The machine should be safe such that there is no fear of its failure under its operation and it should be hazard-free for the worker

- It should not damage the food quality by deteriorating its ingredients and there should be no adulteration of meat products inside machine

- The machine should be easy to operate and even an uneducated person should be able to run

- The starting/setup time should be lower that will reduce the lead time.

- Machine should be design and controlled such that it is suitable for stage cooking

- The machine should be portable such that it can be conveyed for barbecuing in different locations

- The barbecue machine should have greater lifetime and on top of that it should be well maintainable

- This machine should be used to barbecue different foods like beef, mutton and chicken etc.

\section{Literature review}

A comprehensive review is the essential for the proposed research work. The prime objectives of gathering the review of literature is to gain background knowledge of various researches and designs that are related to our work and to identify appropriate product design, method of measuring concepts, analyze the data collected, utilize the techniques to evaluate and discuss the data collected. Study by the Schwela [1] found that total suspended particulate and $\mathrm{PM}_{10}$ level remain above the WHO guidelines for 20 specific regions of Asia. Gurjar et al. [2]) analyzed the quality of air in different cities of the world and concluded five cities as having 'fair' air quality and 13 as 'poor'. They suggested a multi-pollutant index (MPI) which takes into account the combined level of the three World Health Organization criteria pollutants (TSP, $\mathrm{SO}_{2}$, and $\mathrm{NO}_{2}$ ). Karachi appeared to be the top polluted city w-r-t TSP and $4^{\text {th }}$ w-r-t MPI.

Parekh et al. [3] reported total suspended particles (TSP) in Karachi and Islamabad over the period of 10 December 1998 to 8 January 1999. They quote average daily TSP concentrations at Karachi in the range $627-928 \mu \mathrm{g} / \mathrm{m} 3$ while those at Islamabad were between 428 and $998 \mu \mathrm{g} / \mathrm{m} 3$. The average levels of $\mathrm{PM}_{10}$ measured by Hashmi and Khani [4] with a mobile monitoring laboratory at the Sindh Industrial Trading Estate and Korangi Industrial Area (Karachi) were 176.5 and $147.2 \mu \mathrm{g} / \mathrm{m} 3$, respectively. Biswas et al. [5] reported the average $\mathrm{PM}_{2.5}$ mass concentration to be many fold higher in Lahore than New York City, Hong Kong, and Seoul. In a study conducted by Pak-EPA and JICA [6] in three cities of Pakistan (Rawalpindi, Islamabad, and Lahore), the concentration of $\mathrm{NO}_{\mathrm{x}}$ and $\mathrm{PM}_{10}$ was found to be higher than WHO guideline. Hourly maximum concentration of CO has been reported as $3.3 \mathrm{ppm}$ in Islamabad. Similarly, Waheed et al. [7] reported PM concentrations in four cities and concluded that levels of SPM in Gujranwala $\left(53-649 \mu \mathrm{g} / \mathrm{m}^{3}\right)$, Faisalabad $\left(111-435 \mu \mathrm{g} / \mathrm{m}^{3}\right)$, Rawalpindi $\left(8451,870 \mu \mathrm{g} / \mathrm{m}^{3}\right)$, and Lahore $\left(1,128-1,870 \mu \mathrm{g} / \mathrm{m}^{3}\right)$ were exceedingly unhealthy. A similar study was conducted by Qadir and Zaidi [8] in Faisalabad. The average mass of TSP was $550 \mu \mathrm{g} / \mathrm{m}^{3}$ with a range of $467-600 \mu \mathrm{g} / \mathrm{m}^{3}$.

Study conducted by UBUOHA and NWAJIOBI, table 2.3, show the concentration of the various pollutants $\mathrm{CO}_{2} \mathrm{SO}_{2}, \mathrm{NO}_{2}$ and $\mathrm{PM}_{2.5}$ in the urban environment varied with the household cooking methods. The results showed that in urban settlement, gas cooking produced least of all four pollutants, which was significantly less than the amounts produced by Firewood stove for all the four pollutants; Kerosene stove : $\mathrm{CO}_{2}$ and $\mathrm{SO}_{2}$, Charcoal stove : $\mathrm{CO}, \mathrm{SO}_{2}$ and $\mathrm{PM}_{2.5}$; and Electric stove for $\mathrm{CO}$ and $\mathrm{SO}_{2}$ respectively. In semi urban settlement, the 
results also indicated that, fire wood stove recorded the highest levels of all the pollutants. The least values were recorded in the gas cooker. The result agreed with Aho, J. A. [9], who reported that the use of firewood as source of heating and energy for cooking and lighting causes indoor air pollution and imperils families to air pollution.

A study conducted by Yuejing ZhaoBin Zhao [10] show a comprehensive method to compare the results of different researches. PM concentration released during cooking of different meats and other foods using different cooking methods and fuels are shown. This study was carried out which is more related with Asian cooking and the data that they extracted can be assume to be true for Pakistani restaurants. The carcinogenicity of some PAHs is well known in animals of laboratory. Researchers have registered increased incidences of lung, skin, bladder, liver, and stomach cancers, as well as injection-site sarcomas, in animals. Animal studies show that certain PAHs also can affect the hematopoietic and immune systems and can produce reproductive, neurologic, and developmental effects [Dasgupta and Lahiri [11, 12]; Hahon and Booth [13], Philips et al. [14]; Szczeklik et al. [15], Zhao et al. [16].

The formation of PAHs varies by meat type, cooking method, and "doneness" level (rare, medium, or well done). Whatever the type of meat, however, meats cooked at high temperatures, especially above $300^{\circ} \mathrm{F}$ (as in grilling or pan frying), or that are cooked for a long time tend to form more PHAs. For example, well-done, grilled, or barbecued chicken and steak all have high concentrations of PHAs. Cooking methods that expose meat to smoke contribute to PAH formation. Lung cancer is the leading cause of cancer-related death in both men and women responsible for 1.59 million deaths around the world in 2012 [17]. Approximately $90 \%$ of lung cancer cases are related to tobacco smoking and 1-2\% are accounted for by outdoor air pollution. Inhalation of incomplete indoor/outdoor combustion of coal and wood induce lung cancer Reid et al [18]. It was discovered at the early stages of development of barbecue that changing and maintaining the temperature during course of cooking can highly enhance the flavor as well as nutrition of food being cooked. Till now, it has been considered in various grills during its design by its manufacturers. Different methods for controlling the temperature inside cooking space of grills have been adopted.

\section{Basic component design and material selection}

This section incudes design and calculations of components of barbecue machine based on the standard procedures followed in mechanical design. Further it gives specification of materials that have been used in this machine. Main components of barbecue machine are motor, chain drive system, insulation, chamber main body frame, outer rigid structure, chamber side packets, burners, chamber separation layer, transparent door, control system, battery, gas cylinder.

\subsection{Design of chain drive system}

This system has chain to sprocket arrangement to support the barbecue and to transmit the power. This machine uses 127 pitch length chains arranged opposite to each other. Eight sprockets are used to engage the chain to desired path. Besides its, clips are also riveted to the chains to work as a skewer holder. We will design chain drive mechanism for our system from two major perspectives i.e. ability of chain drive system to transmit the power across the whole structure to carry the food there for cooking and secondly the ability of chain and sprocket to withstand the corrosive and hot thermal environment. Step by step approach for the design of chain drive system is as below:

Step 1: First of all calculate the velocity ratio (VR) of the system

$\mathrm{VR}=\mathrm{N} 1 / \mathrm{N} 2=\mathrm{T} 2 / \mathrm{T} 1$

Here N1, N2 are speeds and T1, T2 are teeth counts of driving sprocket and driven sprockets respectively

Step 2: As we know that in this case of transmitting the power to the other sprockets from the motor driven sprocket one must keep the speed and teeth numbers of each sprocket constant that is $\mathrm{T} 1=\mathrm{T} 2$ or $\mathrm{N} 1=\mathrm{N} 2$ so Velocity ratio $=1$

Step 3: From selector chart, select proper chain pitch \& drive sprocket. We choose 20 teeth sprocket and ANSI 41 number chain because it is easily available in market and we check for its power rating and whether it suits our application.

Step 4: From equation (1): V.R $=1=\mathrm{T} 2 / \mathrm{T} 1 \mathrm{~T} 2=\mathrm{T} 1=20$

Step 5: Calculate the design power (DP) as

$\mathrm{DP}=$ rated power $(\mathrm{RP}) *$ service factor $(\mathrm{S})$

Service factor $=\mathrm{S}=\mathrm{S}_{1} * \mathrm{~S}_{2} * \mathrm{~S}_{3}$

Where, $S_{1}=1.25$, for variable and mild shock, $S_{2}=1.5$, for periodically lubrication and $S_{3}=1$ for $6-8$ hours of operation daily. So from equation (3) $\mathrm{S}=1.25 * 1.5 * 1=1.878$

From equation (2), Design power $=1.878 * 50$ watts $=93.9$ watts

Step 6: Considering 41 ANSI chain with pitch of 0.5 inch, to be used with 20 teeth sprocket Richard G. Budynas, J. Keith Nisbett [2008]. We also check manufacturer's catalog for final stock selection. We have data for small sprocket speed of 10, 25, $50 \mathrm{rpm}$ and so on.

Step 7: If we look across 20 teeth sprocket specifications, we find horsepower rating of $0.18 \mathrm{hp}$ which satisfy its application for our design power, where we know our design speed of sprocket is in between 10 and $30 \mathrm{rpm}$.

Step 8: Review Horsepower standard tables for type of lubrication required which is type A.

Step 9: For sprocket dimension that are used and compatible with chain no 41 can be seen from the table published by American standards for sprocket tooth dimensions.

Step 10: For sprocket diameter we refer to same American standards and look for sprocket dimensions used with roller chain 41 sprocket diameters.

Table 1: Specifications of Selected Chain Drive System

\begin{tabular}{ll}
\hline Parameter & Description \\
\hline Chain number (ANSI) & 41 \\
No of strands & 1 \\
Lubrication type & A, manual or drip lubrication \\
Pitch of chain & 0.5 inch \\
\hline
\end{tabular}




\begin{tabular}{ll} 
Roller diameter of chain & 0.306 inch \\
Width of chain & 0.25 inch \\
Breaking load for chain & $6.670 \mathrm{kN}$ \\
Pitch diameter of sprocket of 20 teeth & 3.196 inch \\
Outside diameter of sprocket & 3.457 inch \\
Sprocket tooth thickness & .227 \\
Sprocket type & $\mathrm{C}$ \\
Material of sprocket & $\mathrm{C} 45$ steel \\
\hline
\end{tabular}

\subsubsection{Properties of chain and sprocket material}

This section provides thermal stability of sprockets and chain, whether it is safe to work under the highest maximum temperature reached inside the cooking space and in presence of moisture contents that are present at the very time of cooking. There are materials that are used in manufacturing of sprockets and chains for standard dimensions.

For Sprockets:

Material: C45 steel

Melting temperature: $1520 \mathrm{C}^{\mathrm{o}}$

Strength: $610 \mathrm{MPa}$

Corrosive resistance: Good MPY

Thermal strain in sprockets $=\alpha \Delta \mathrm{T}$

Thermal strain $=11.1 \times 10^{-6} \times 100=0.00111$ metre

For Chains:

Material: AISI 2330

Composition of AISI 2330 material is as follows:

Table 2: Composition of AISI 2330 material.

\begin{tabular}{lllllll}
\hline Element & $\mathrm{C}$ & $\mathrm{Mn}$ & $\mathrm{P}$ & $\mathrm{S}$ & $\mathrm{Si}$ & $\mathrm{Ni}$ \\
\hline Weight $\%$ & 0.33 & 0.78 & 0.014 & 0.035 & 0.09 & 3.59 \\
\hline
\end{tabular}

Elastic modulus: $195 \mathrm{GPa}$

Poission's ratio: 0.285

Thermal expansion: $13.6 \mu \mathrm{m} / \mathrm{C}^{\mathrm{o}}$

Thermal strain for chains $=\alpha \Delta \mathrm{T}=13.6 \mu \times 100=0.00136$ metre

\subsection{Insulation}

Insulation Materials is Rockwool and Castable Refractory Cement. Now to calculate the heat lost to environment, we need convective coefficients inside and outside the machine. For the range of 2 to $20 \mathrm{~m} / \mathrm{s}$, the coefficient of heat is.

$\mathrm{hc}=10.45-\mathrm{v}+10 \mathrm{v}^{1 / 2}$

Average air speed is $7 \mathrm{miles} / \mathrm{hr}$ or $3.13 \mathrm{~m} / \mathrm{s}$. from equation $(1) \mathrm{h}_{2}=\mathrm{h}_{\mathrm{c}}=25.012 \mathrm{~W} / \mathrm{m}^{2} \mathrm{~K}$. In range of temperature of $100-250 \mathrm{C}^{\circ}$, the convective heat transfer coefficient varies between 45 to $65 \mathrm{~W} / \mathrm{m}^{2} \mathrm{~K}$. so we take its average which is $\mathrm{h}_{1}=55 \mathrm{~W} / \mathrm{m}^{2} \mathrm{~K}$ for the inside of machine. We have the governing equation of energy balance as

$\mathrm{q}_{\text {in }}=\mathrm{q}_{\text {lost }}+\mathrm{q}_{\text {exhast }}+\mathrm{q}_{\text {acc }}$

qin $=\mathrm{mf}^{*}$ calorific value

$\mathrm{q}_{\text {lost }}=(\mathrm{T} 1-\mathrm{T} \infty) /[1 / \mathrm{A}(1 / \mathrm{h} 1+\mathrm{v} 1 / \mathrm{S} 1+\mathrm{v} 2 / \mathrm{S} 2+\mathrm{v} 3 / \mathrm{S} 3+\mathrm{v} 4 / \mathrm{S} 4+1 / \mathrm{h} 2)]$

Where $v_{1}, v_{3}$ are steel and $v_{2}$ is the thickness of Rockwool insulation and $v_{4}$ of cast able refractory cement material. We have $v_{1}=v_{3} . S_{1}, S_{3}$ are steel thermal conductivity and $\mathrm{S}_{2}$ is thermal conductivity of Rockwool and $\mathrm{K}_{4}$ of cement insulation material. $\mathrm{S}_{1}=\mathrm{S}_{3}$

Table 3: Data for Finding Q Lost

\begin{tabular}{llll}
\hline $\begin{array}{l}\mathrm{S}_{1}, \mathrm{~S}_{3} \\
\left(\mathrm{w} / \mathrm{m}^{-1}\right)\end{array}$ & 21 & $\begin{array}{l}\mathrm{v}_{2} \\
(\mathrm{~m})\end{array}$ & 0.0254 \\
\hline $\begin{array}{l}\mathrm{S}_{2} \\
\left(\mathrm{w} / \mathrm{m} \cdot \mathrm{k}^{-1}\right)\end{array}$ & 0.022 & $\begin{array}{l}\mathrm{T}_{1} \\
\left(\mathrm{C}^{\circ}\right)\end{array}$ & 200 \\
$\mathrm{~S}_{4}$ & 0.35 & $\begin{array}{l}\mathrm{T}_{\infty} \\
\left(\mathrm{w} / \mathrm{m} \cdot \mathrm{k}^{-1}\right)\end{array}$ & $\begin{array}{l}\left.\mathrm{C}^{\circ}\right) \\
\left(\mathrm{m}^{2}\right)\end{array}$ \\
$\begin{array}{l}\mathrm{h}_{1} \\
\left(\mathrm{w} / \mathrm{m}^{2} \cdot \mathrm{k}\right)\end{array}$ & 55 & $\mathrm{v}_{4}$ & 25 \\
$\mathrm{~h}_{2}$ & & & $1.4286 / 2=0.7143$ \\
$\left(\mathrm{w} / \mathrm{m}^{2} \cdot \mathrm{k}\right)$ & 25.012 & & $0.00254(\mathrm{~m})$ \\
$1, \mathrm{v}_{3}$ & 0.000953 & & \\
$(\mathrm{~m})$ & & & \\
\hline
\end{tabular}

From equation (2) after solving, we have qlost for maximum temperature ranges. 


\subsection{Calculation of power of motor}

It is essential to know the power required to drive the system which is essential for selection of motor. On the basis of the chain selected of pitch length, $\mathrm{p}=0.5$-inch, one can weld the skewer holder on 1 inche distance which is two pitches of chain. We leave two links of chain without welding skewer holder to it to have enough space for cut of meat. We keep 3 inches space between two consecutive skewers and considering 1.5 inches cuts of meat, it allows us to have 1.5 inches space between two cut of meats. In figure 3.1, show the dimensions discussed above with only two skewer and 2 cuts of meat in each skewer for calculation purpose.

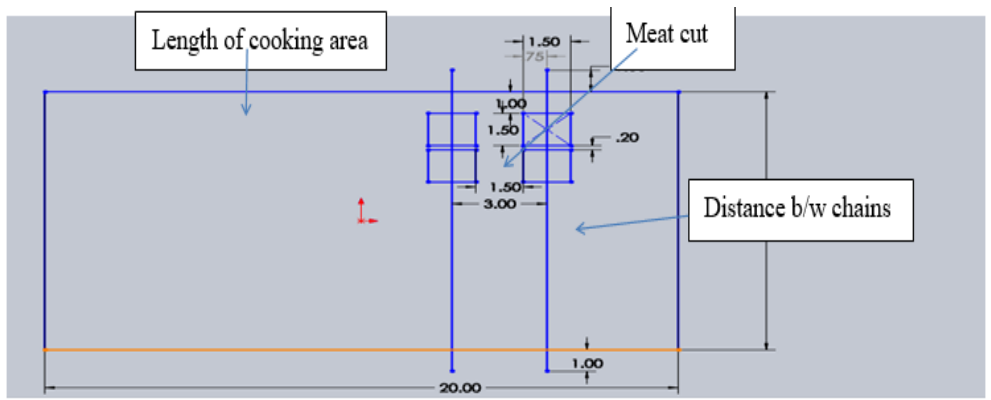

Fig. 2: Dimensions of Skewers, Chains and Spacing between Skewers, Meat Cuts.

Now we calculate the mass supported by motor;

Total mass $=$ mass of food + mass of skewers + mass of chain

Skewer is 14 inch in length but we can utilize only 10 inches for holding cuts of meat. Length occupied by one piece of meat is 1.7 inches, where 0.2 inch is spacing between two pieces. Number of meat cuts in 10 inches (one skewer) $=10 / 1.7=5.88 \approx 6$ pieces. Now we are designing the machine for three types of food mutton, beef and chicken. So, we calculate the mass of one cut of meat on the basis of heaviest food.

Mass of one piece of meat $=\rho_{\max } * \mathrm{v}$

Volume of one piece $=\mathrm{v}=1.5^{\wedge} 3=3.375 \mathrm{in}^{3}=5.53 * 10^{-5} \mathrm{~m}^{3}$

$\rho_{\max }=\max \left\{\rho_{\text {mutton }}=1487, \rho_{\text {chicken }}=930, \rho_{\text {beef }}=1420\right\}=1487 \mathrm{~kg} / \mathrm{m}^{3}$ using equation (2),

Mass of one piece of meat $=1487 * 5.53 * 10^{-5}=0.0822 \mathrm{~kg}$

Mass of food in one skewer $=6 * 0.0822=0.493 \mathrm{~kg}$

Now length is 20 inches so total number of skewers in this length is $=1+20 / 3=7.66 \approx 7$ skewers

Total mass of food in 7 skewers $=0.493 * 7=3.451 \mathrm{~kg}$

Considering skewers of $6 \mathrm{~mm}$ or 0.23622 inch of diameter, and length 1 , of one skewer is 14 inch

Volume of one skewer $\mathrm{v}_{\mathrm{s}}=\mathrm{A} * 1=\pi / 4 * \mathrm{~d}^{2 *} \mathrm{l}=\pi / 4 *\left(6 * 10^{-3}\right)^{2 *}\left(355.6 * 10^{-3}\right)=1.0054 * 10^{-5} \mathrm{~m}^{3}$

Material used for skewer is stainless steel whose density is $8000 \mathrm{~kg} / \mathrm{m}^{3}$.

So mass of one skewer is $=\mathrm{v}_{\mathrm{s}} * \rho_{\text {steel }}=1.0054 * 10^{-5} * 8000=0.08043 \mathrm{~kg}$

Mass of 7 skewers $=7 * 0.08043=0.563 \mathrm{~kg}$

Mass of chain is calculated here which also contribute toward the power consumption. So the chain used has average mass of 0.37245 $\mathrm{kg} / \mathrm{m}$. total chain length used on both sides of skewer is approximately $140 \mathrm{inch}=3.556 \mathrm{~m}$ and

Total mass of chain is $=0.37245 * 3.556=1.3244 \mathrm{~kg}$

Total mass $=3.451+0.563+1.3244=5.3384 \mathrm{~kg}$

Total mass is $5.71 \mathrm{~kg}$ when we consider $+7 \%$ uncertainties in calculations. Two forces are acting on chain, figure 3.2 , where tension is created by motor in chain to balance the downwards acting weight.

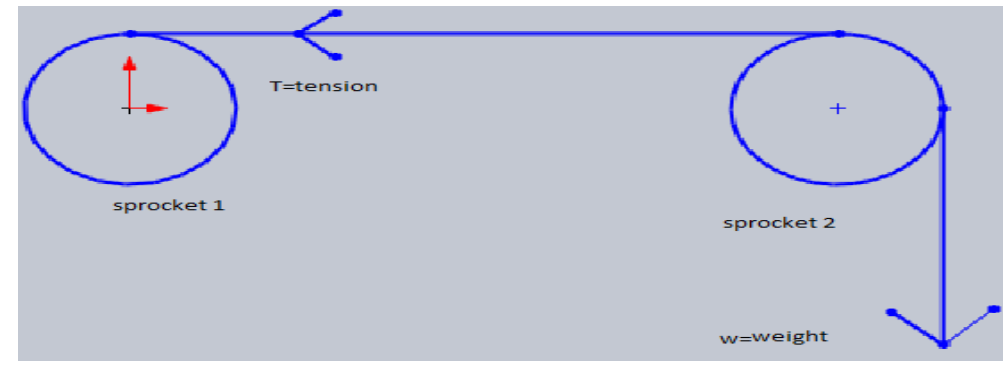

Fig. 3: Free Body Diagram of Chain

In balance condition of forces, we have 
$\Sigma \mathrm{F}=0=\mathrm{T}-\mathrm{W}=0 \mathrm{~T}=\mathrm{W}$

$\mathrm{W}=\mathrm{mg}=5.71 * 10=57.1 \mathrm{~N}$

The velocity at which chain moves is calculated on assumption that stage shift occurs in 15 seconds and total distance travelled in this time is 35 inches. So, $\mathrm{s}=\mathrm{vt}, \mathrm{v}=\mathrm{s} / \mathrm{t}, \mathrm{v}=35 / 15=2.3333 \mathrm{inch} / \mathrm{sec}$ or $\mathrm{v}=0.05926 \mathrm{~m} / \mathrm{s}$

Power $=\mathrm{F}^{*} \mathrm{v}=57.1 \mathrm{~N} * 0.05926 \mathrm{~m} / \mathrm{s}=3.384$ Watts

We know $\mathrm{v}=\mathrm{r} * \omega \omega=\mathrm{v} / \mathrm{r}=0.05926 / 0.0508=1.16653 \mathrm{rad} / \mathrm{s}=15.90244 \mathrm{rpm}$

Some of the power will be required to overcome the frictional torque of 8 bearings used.

We have frictional torque of bearings $=\mathrm{n} * \mathrm{p} * \mu * \mathrm{~d}_{\mathrm{m}} / 2$

Where $\mathrm{n}=8$, and frictional coefficient $\mu=0.0015$ for ball bearing. $\mathrm{P}=57.1 \mathrm{~N}$, diametric pitch $\mathrm{d}_{\mathrm{m}}=\mathrm{d}(\mathrm{o})+\mathrm{d}(\mathrm{i}) / 2$

From equation (6) torque frictional $=8 * 57.1 * 0.0015 * 0.05 / 2=0.01713$ N.m

Power frictional $=0.01713 * 1.16653=0.019983$ watts

From the available literature we consider $97 \%$ chain drive mechanical efficiency and $95 \%$ gear transmission mechanical efficiency. So, we have

Total power $=3.384+0.019983 / 0.95 * 0.97=3.6939$ watts

Using Factor of safety as 3 we have $3 * 3.6939=11.08$ watts. We use motor with power greater than 11.08 watts.

\subsection{Main frame outer rigid structure}

Material selected to fabricate the main frame of barbecue machine is A36 angle carbon steel which is generally easy to form, weld and machine and also to increase resistance to corrosion. Chemical composition and mechanical properties and angle specification of A36 angle carbon steel are shown in the following tables.

\begin{tabular}{llllll}
\multicolumn{7}{c}{ Table 4: A36 Carbon Steel Angle Chemical Composition } \\
\hline Steel Grade & Carbon, Max, \% & Manganese, $\%$ & Phosphorus, Max, \% & Sulfur, Max, \% & Silicon, \% \\
\hline A36 & 0.26 & --- & 0.04 & 0.05 & $\leq 0.40$ \\
\hline
\end{tabular}

Table 5: A36 Carbon Steel Angle Mechanical Property

\begin{tabular}{lll}
\hline Steel grade & Tensile Strength, ksi [MPa] & Yield Point, min, ksi [MPa] \\
\hline A36 & $58-80[400-550]$ & $36[250]$ \\
\hline
\end{tabular}

Table 6: A36 Equal Angle Steel Specification

\begin{tabular}{lllll}
\hline Item number & Leg 1 & Leg 2 & Thickness & Weight $(\mathrm{kg} / \mathrm{m})$ \\
\hline EA36004 & $25 \mathrm{~mm}$ & $25 \mathrm{~mm}$ & $4 \mathrm{~mm}$ & 1.459 \\
\hline
\end{tabular}

\subsection{Chamber side packets}

Material Type: 430 Stainless Steel

Melting Point: $1450-1510 \mathrm{C}^{\circ}$

Table 7: Chemical Composition of Stainless-Steel Type 430 Material

\begin{tabular}{|c|c|c|c|c|c|c|c|}
\hline Material & $\mathrm{C} \%$ & $\mathrm{Mn} \%$ & $\mathrm{Si} \%$ & $\mathrm{P} \%$ & $\mathrm{~S} \%$ & $\mathrm{Cr} \%$ & $\mathrm{Ni} \%$ \\
\hline Stainless steel type 430 & 0.12 & 1 & 1 & 0.04 & 0.030 & 18 & 0.50 \\
\hline Material Strength & & Ten & & Yie & & Brin & \\
\hline Stainless steel type 430 & & 483 & & 310 & & 183 & \\
\hline
\end{tabular}

Heat Resistance: Its average resistance is $870^{\circ} \mathrm{C}$ and $815^{\circ} \mathrm{C}$ for intermittent and continuous usage respectively. Its average thermal conductivity is $26.2 \mathrm{~W} / \mathrm{m} . \mathrm{K}^{-1}$.

Corrosion Resistance: Very excellent especially for acids such as nitric acid.

Dimensions: are presented as below in the table

\begin{tabular}{llll}
\hline S. No & Position of piece to be placed & Dimension (Inches) & Quantity \\
\hline 1. & Right and left side & $17.8 \times 15.9$ & 2 \\
3. & Back side & $27.9 \times 17.9$ & 1 \\
4. & Front side & $17.9 \times 5.8$ & 2 \\
5. & Top and down side & $27.8 \times 15.9$ & 2 \\
\hline
\end{tabular}

\subsection{Burners}

Infrared burners are used as heat element. These burners perform cooking with the help of radiation. With infrared burners there are less chances of flare ups and it produces even and intense heating.

Dimensions: $(11.5 * 4.5)$

Number of Burners: 2

Ignition Mode: Pilot

Casing Material: Stainless Steel

Burner Material: Ceramic Plate

Heat Output: $2700 \mathrm{kcal} / \mathrm{hour}$ 


\section{Cad modeling of barbecue machine}

Cad design for the proposed machine is created using computer aided design software i.e. Solid works. Solid works offers a range of tool that enables us to produce a geometrically precise model for our product. Initially all the components used in our machine were created separately as parts. The parts are assembled by adding parts step by step to the main machine using the assembly features of the Solid works. The parts are assembled to get desired model of machine. To achieve this all components made are browsed and dropped into assembly document of Solid works which is shown below.

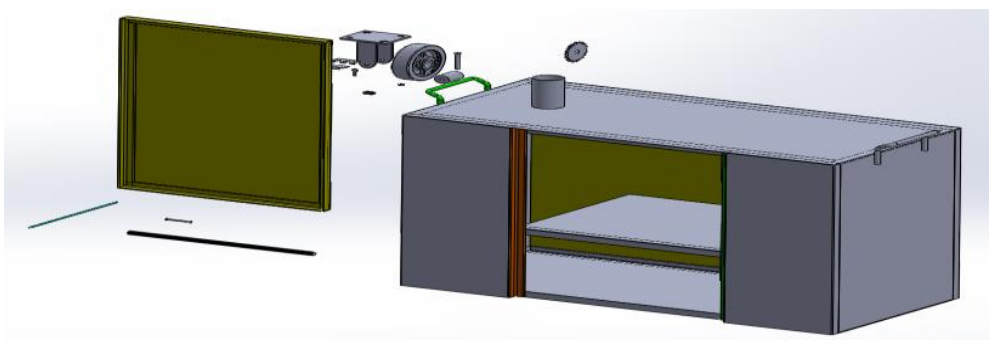

Fig. 4: Parts To Assemble.

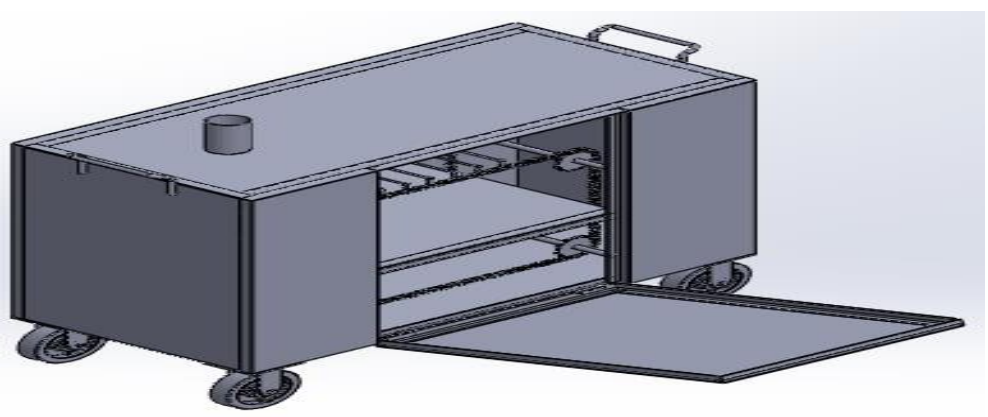

Fig. 5: Final Cad Model of Our Machine.

\section{Fabricating the barbecue machine}

This section presents the secondary manufacturing processes where the starting raw materials are produced by any one of the previous manufacturing processes desired. Their assemblies involve joining pieces either temporary or permanent. So that they would be perform the necessary function. The joining can be achieved by either or both of heat and pressure joining materials.

\subsection{Fabricating the main frame}

Fabrication of machine main frame starts from construction of the outer rigid structure made of A36 steel. For this four cuts of 28 inches are made into A36 steel bars with the help of angle grinder of 4-1/2inches grinder. Similarly, four cuts of 16 inches and four of 18 inches are made. These cut pieces are welded through electric welding to form a cubical shape of length 28 -inch, height 18 inch and width 16 inch. Finally ridges and raises on the welded surface are removed with surface grinder wheel. Upper burner of the lower is assembled to the covering of chamber separation layer by welding screw and attaching it with burner through square washer, figure 5.1

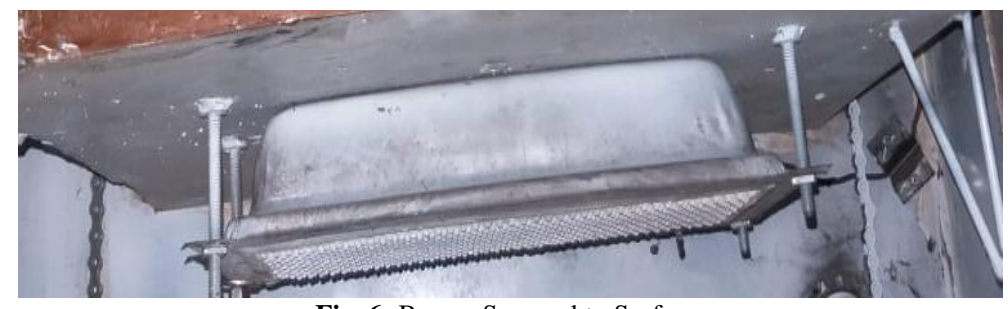

Fig. 6: Burner Screwed to Surface.

The frame of the door is assembled to the frame of the door by fitting the tem in tempered glass and bending the clips. The silicon solution is applied to glass sheet to firmly fix it with door frame. Supporting frame is made by welding four 4.5 inches long hollow pipe to the main body and attaching wheels to it. The end product fabricated is as shown in figure 5.2.

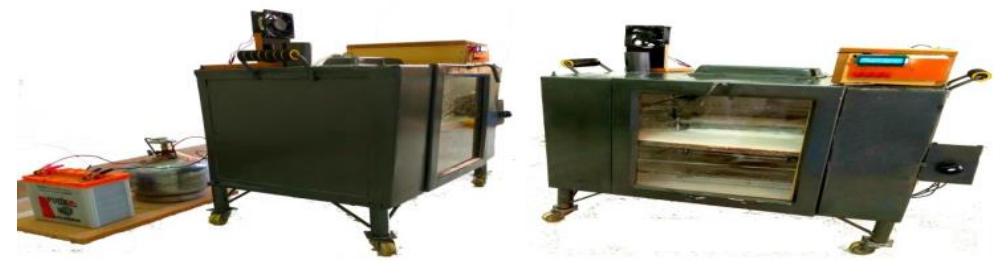

Fig. 7: Fabricated End Product. 


\section{Results and discussions}

\subsection{Gas consumption rate}

Gas consumption test was carried out by running machine for duration more than 500 minutes. For sake of comparison gas consumption in conventional method BBQ making is also monitored for this much time. Weight of cylinder containing fuel is measured at step time of 50 minutes. Following graph is developed based on this measurement which shows that fuel consumption of fuel in our machine is lower than that of conventional BBQ making methods.

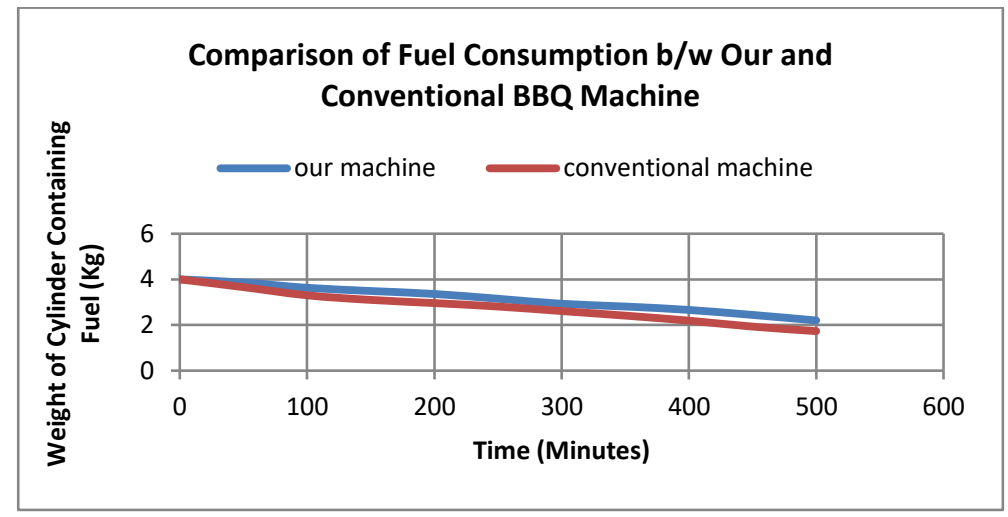

Fig. 8: Comparison of Fuel Consumption B/W Our and Conventional Bbq Machine.

This can also be represented in terms of cost as in following figure 6.2.

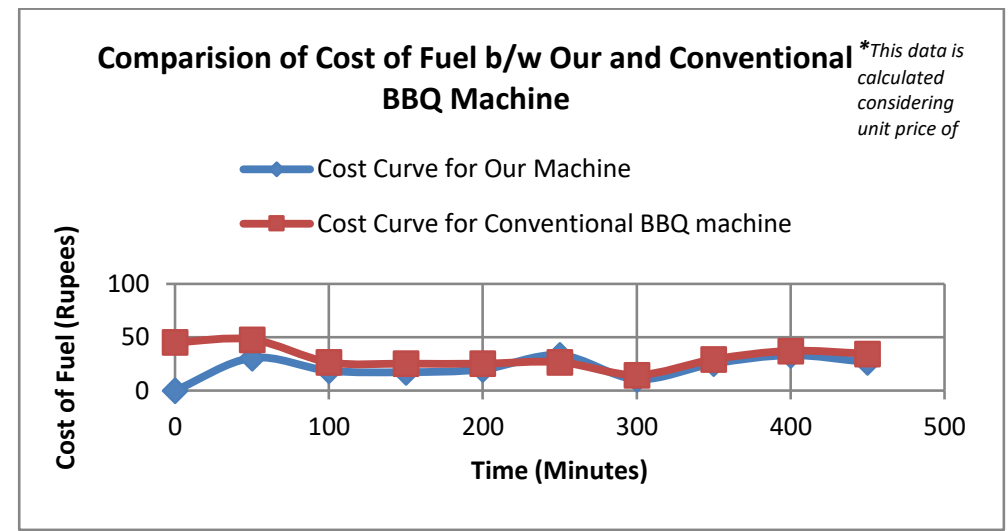

Fig. 9: Comparision of Cost of Fuel B/W Our and Conventional Bbq Machine.

\subsection{Speed test}

Due to inertia and friction rack is not always stopped at the desired central location. It is stopped at lagging or leading from this point. But when these are summed up it rack stays nearer to the required position as given below.

Table 9: Speed Test

\begin{tabular}{|c|c|c|c|c|}
\hline Time & Lag & Lead & Distance in each cycle (lag or lead) & Total offset in 5 cycles \\
\hline 1 & 0.015 & 0.001 & 0.014 & \multirow{5}{*}{-0.056} \\
\hline 2 & 0.05 & 0.1 & -0.05 & \\
\hline 3 & 0 & 0.01 & -0.01 & \\
\hline 4 & 0.2 & 0.11 & 0.09 & \\
\hline 5 & 0 & 0.1 & -0.1 & \\
\hline
\end{tabular}

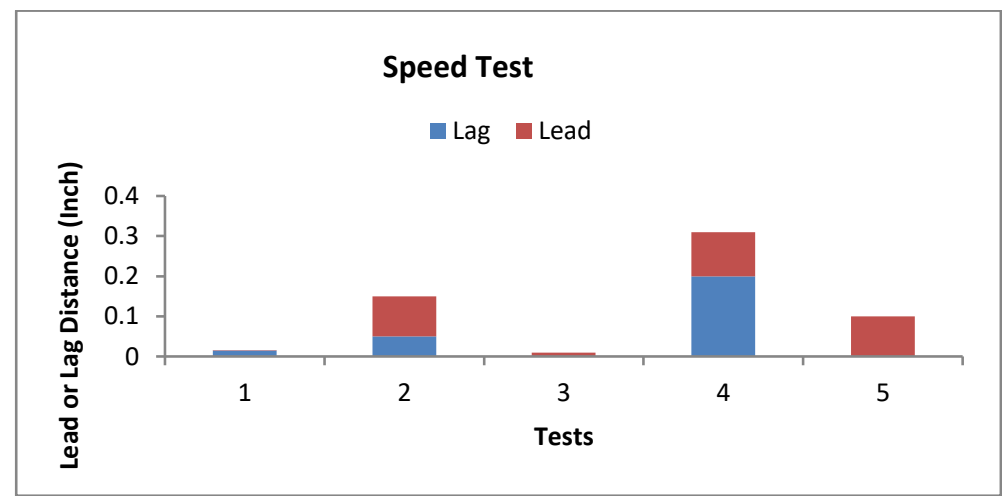

Fig. 10: Lag and Lead of Rack from Its Ideal Position in Each Test. 


\subsection{Control test}

To check control portion of machine few tests were carried out. Here we checked the following.

- Settings, increment, decrement and start buttons are working and perform its designed action.

- The solenoid valve can cut off the flow when temperature matches set point temperature.

- It shows temperature and time values on LCD screen.

- It can shift rack between two stages at the time selected.

- Motor is working and activated for programmed time.

- It can turn ON/OFF exhaust fan for time we have programmed.

\subsection{Food test}

Chicken was barbecued few times to see quality consistency, internal shape and physical appearance of chicken. Quality of food was consistent in terms of its color, texture and moist inside it. Secondly there was no raw portion inside of chicken pieces due to even heating. Apart from it there was less/no ash or smoke black particles on the exterior surface of chicken which represent no food adulteration. A chicken test sample is shown in figure 7.4.

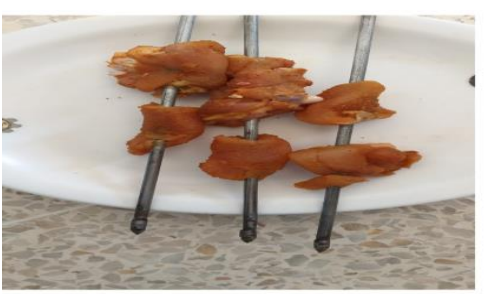

Before

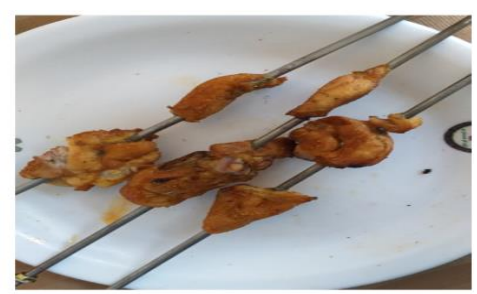

After

Fig. 11: Food Test.

\subsection{Battery discharge time}

We must know the battery discharge time in order to plan battery replacement. Here we are using 10 AH battery. And motor's load current is $2.5 \mathrm{~A}$. So it can be used for, $10 / 2.5=4$ hours $=14400$ seconds, of constant operation. It means that if we are just barbecuing chicken and so it will be discharged after 144 hours of constant running.

\subsection{Cycle time and productivity}

The cycle time has been reduced to 6 minutes from 9 minutes and 30 seconds for barbecuing chicken. It stays for 2.5 minutes in first stage for $55 \mathrm{C}^{0}$ and 3.5 minutes in second stage for $90 \mathrm{C}^{0}$ temperatures. So, the overall effect is to reduce the cycle time to barbecue. Besides this, its volume to mass ratio is 0.0033 , which is better than 0.00265 of conventional BBQ machines. It offers more cooking space per kg of product weight and hence it is of higher productivity.

\section{Conclusion and future recommendations}

We conclude our work by mentioning its some achievements and impact level it would create once it is commercialized. The following points can be concluded from the proposed research:

- Mechanization and automation in road side barbecuing machines can significantly increase and efficiency of such machines.

- The heat input needed per unit food barbecued can be reduced, and more fuel can be conserved

- Stage cooking of using two sets of temperature and time result in ideal barbecuing.

- The problem of carcinogenetic barbecue can be reduced here.

- The unnecessary worker's movements can be eliminated. He doesn't need to monitor the process all through the cycle.

- Small setup time of this machine reduces lead times and hence higher customer satisfaction can be achieved.

- The machine is safe to use (because it has emergency shutoff switch), as compared to conventional barbecuing methods.

- Low and intermittent power requirement makes it more energy efficient as compared to barbecuing done through constant rotation by motor.

- Automatic shutoff of gas supply after use makes is it's another advantage.

- It has safe to touch exterior as compared to conventional methods which have high rates of heat burns.

\section{References}

[1] Gurjar, B. R., Jain, A., Sharma, A., Agarwal, A., Gupta, P., Nagpure, A. S., \& Lelieveld, J, "Human health risks in megacities due to air pollution", Atmospheric Environment, vol. 44, no. 36, pp. 4606-4613, 2010. https://doi.org/10.1016/j.atmosenv.2010.08.011.

[2] Schwela, D., Haq, G., Huizenga, C., Han, W.J., Fabian, H., Ajero., M, "Urban Air Pollution in Asian Cities", London: Routledge, 2006.

[3] Richard G. Budynas, J. Keith Nisbett, Shigley’s mechanical engineering design, 8th ed. (McGraw-Hill series in mechanical engineering)

[4] Alan S. Morris; Reza Langari, Measurement, and instrumentation: theory and application.

[5] Groover, Mikell P. Fundamentals of modern manufacturing: materials, processes and systems, 4th edition.

[6] Jägerstad M, Skog K, "Genotoxicity of heat-processed foods. Mutation Research", vol. 574, no. 1-2, pp. 156-172, 2005. https://doi.org/10.1016/j.mrfmmm.2005.01.030.

[7] Parekh, Bhikhu. "Rethinking multiculturalism: Cultural diversity and political theory." Ethnicities 1.1 pp. 109-115, 2001. https://doi.org/10.1177/146879680100100112. 
[8] Hashmi, D. R., \& Khani, M. I. Q, "Environmental impact assessment of air pollution in different areas of Karachi [Pakistan]", Pakistan Journal of Scientific and Industrial Research (Pakistan), 2003.

[9] JICA, C, "The study on seismic microzoning of the Greater Tehran Area in the Islamic Republic of Iran", Pacific Consultants International Report, OYO Cooperation, Japan, pp. 291-390. 2000.

[10] Biswas, S., Verma, V., Schauer, J. J., \& Sioutas, C, "Chemical speciation of PM emissions from heavy-duty diesel vehicles equipped with diesel particulate filter (DPF) and selective catalytic reduction (SCR) retrofits", Atmospheric Environment, vol. 43, no. 11, pp. 1917-1925, 2009. https://doi.org/10.1016/j.atmosenv.2008.12.040.

[11] Duman, R. S., \& Monteggia, L. M, "A neurotrophic model for stress-related mood disorders", Biological psychiatry, vol. 59, no. 12, pp. 1116-1127, 2006. https://doi.org/10.1016/j.biopsych.2006.02.013.

[12] Qadir, M. A., \& Zaidi, J. H, "Characteristics of the aerosol particulates in the atmosphere in an urban environment at Faisalabad, Pakistan", Journal of radioanalytical and nuclear chemistry, vol. 267, no. 3, pp. 545-550, 2006. https://doi.org/10.1007/s10967-006-0084-y.

[13] Aho, J. A, "The orifice as sacrificial site: culture, organization, and the body", Transaction Publishers, 2002.

[14] Chen, C., Zhao, Y., \& Zhao, B, "Emission rates of multiple air pollutants generated from Chinese residential cooking. Environmental science \& technology, vol. 52, no. 3, pp. 1081-1087, 2018. https://doi.org/10.1021/acs.est.7b05600.

[15] Dasgupta, S., \& Lahiri, K, "A comparative study of alternative methods of quantifying qualitative survey responses using NAPM data. Journal of business \& economic statistics, vol. 10, no. 4, pp. 391-400, 1992. https://doi.org/10.1080/07350015.1992.10509914.

[16] Hahon, N., Vallyathan, V., Booth, J. A., \& Sepulveda, M. J, "In vitro biologic responses to native and surface-modified asbestos". Environmental research, vol. 39, no. 2, pp. 345-355, 1986. https://doi.org/10.1016/S0013-9351(86)80060-3.

[17] Horton, D., \& Philips, K. D, "The nitrous acid deamination of glycosides and acetates of 2-amino-2-deoxy-D-glucose". Carbohydrate Research, vol. 30, no. 2, pp. 367-374, 1973. https://doi.org/10.1016/S0008-6215(00)81823-6.

[18] Sladek, K., Dworski, R., Soja, J., Sheller, J. R., Nizankowska, E., Oates, J. A., \& Szczeklik, A, "Eicosanoids in bronchoalveolar lavage fluid of aspirin-intolerant patients with asthma after aspirin challenge". American journal of respiratory and critical care medicine, vol. 149, no.4, 940-946, 1994. https://doi.org/10.1164/ajrccm.149.4.8143059.

[19] Li, H. Q., Chen, S. H., \& Zhao, H. M, "Fractal mechanisms for the allosteric effects of proteins and enzymes", Biophysical journal, vol. 58, no. 5, pp. 1313-1320, 1990. https://doi.org/10.1016/S0006-3495(90)82472-3.

[20] Mathivanan, S., Fahner, C. J., Reid, G. E., \& Simpson, R. J, "ExoCarta 2012: database of exosomal proteins, RNA and lipids", Nucleic acids research, vol. 40, no. 1, pp. 1241-1244, 2011. https://doi.org/10.1093/nar/gkr828. 